\title{
THE STATUS OF LINGUISTICS AS A SCIENCE ${ }^{1}$
}

\author{
E. SAPIR \\ University of Chicago
}

[The long tried methods of Indo-European linguistics have proved themselves by the success with which they have been applied to other fields, for instance Central Algonkian and Athabaskan. An increasing interest in linguistics may be noted among workers in anthropology, culture history, sociology, psychology, and philosophy. For all of them linguistics is of basic importance: its data and methods show better than those of any other discipline dealing with socialized behavior the possibility of a truly scientific study of society. Linguists should, on the other hand, become aware of what their science may mean for the interpretation of human conduct in general.]

Linguistics may be said to have begun its scientific career with the comparative study and reconstruction of the Indo-European languages. In the course of their detailed researches Indo-European linguists have gradually developed a technique which is probably more nearly perfect than that of any other science dealing with man's institutions. Many of the formulations of comparative Indo-European linguistics have a neatness and a regularity which recall the formulae, or the so-called laws, of natural science. Historical and comparative linguistics has been built up chiefly on the basis of the hypothesis that sound changes are regular and that most morphological readjustments in language follow as by-products in the wake of these regular phonetic developments. There are many who would be disposed to deny the psychological necessity of the regularity of sound change, but it remains true, as a matter of actual linguistic experience, that faith in such regularity has been the most successful approach to the historic problems of language. Why such regularities should be found and why it is necessary to assume regularity of sound change are questions that the average linguist is perhaps unable to answer satisfactorily. But it does not follow that he can expect to improve his methods by discarding well tested hypotheses and

${ }^{1}$ Read at a joint meeting of the Linguistic Society of America, the American Anthropological Association, and Sections H and L of the American Association for the Advancement of Science, New York City, December 28, 1928. 
throwing the field open to all manner of psychological and sociological explanations that do not immediately tie up with what we actually know about the historical behavior of language. A psychological and a sociological interpretation of the kind of regularity in linguistic change with which students of language have long been familiar are indeed desirable and even necessary. But neither psychology nor sociology is in a position to tell linguistics what kinds of historical formulations the linguist is to make. At best these disciplines can but urge the linguist to concern himself in a more vital manner than heretofore with the problem of seeing linguistic history in the larger framework of human behavior in the individual and in society.

The methods developed by the Indo-Europeanists have been applied with marked success to other groups of languages. It is abundantly clear that they apply just as rigorously to the unwritten primitive languages of Africa and America as to the better known forms of speech of the more sophisticated peoples. It is probably in the languages of these more cultured peoples that the fundamental regularity of linguistic processes has been most often crossed by the operation of such conflicting tendencies as borrowing from other languages, dialectic blending, and social differentiations of speech. The more we devote ourselves to the comparative study of the languages of a primitive linguistic stock, the more clearly we realize that phonetic law and analogical leveling are the only satisfactory key to the unravelling of the development of dialects and languages from a common base. Professor Leonard Bloomfield's experiences with Central Algonkian and my own with Athabaskan leave nothing to be desired in this respect and are a complete answer to those who find it difficult to accept the large scale regularity of the operation of all those unconscious linguistic forces which in their totality give us regular phonetic change and morphological readjustment on the basis of such change. It is not merely theoretically possible to predict the correctness of specific forms among unlettered peoples on the basis of such phonetic laws as have been worked out for them-such predictions are already on record in considerable number. There can be no doubt that the methods first developed in the field of Indo-European linguistics are destined to play a consistently important rôle in the study of all other groups of languages, and that it is through them and through their gradual extension that we can hope to arrive at significant historical inferences as to the remoter relations between groups of languages that show few superficial signs of a common origin.

It is the main purpose of this paper, however, not to insist on what 
linguistics has already accomplished, but rather to point out some of the connections between linguistics and other scientific disciplines, and above all to raise the question in what sense linguistics can be called a 'science'.

The value of linguistics for anthropology and culture history has long been recognized. As linguistic research has proceeded, language has proved useful as a tool in the sciences of man and has itself required and obtained a great deal of light from the rest of these sciences. It is difficult for a modern linguist to confine himself to his traditional subject matter. Unless he is somewhat unimaginative, he cannot but share in some or all of the mutual interests which tie up linguistics with anthropology and culture history, with sociology, with psychology, with philosophy, and, more remotely, with physics and physiology.

Language is becoming increasingly valuable as a guide to the scientific study of a given culture. In a sense, the network of cultural patterns of a civilization is indexed in the language which expresses that civilization. It is an illusion to think that we can understand the significant outlines of a culture through sheer observation and without the guide of the linguistic symbolism which makes these outlines significant and intelligible to society. Some day the attempt to master a primitive culture without the help of the language of its society will seem as amateurish as the labors of a historian who cannot handle the original documents of the civilization which he is describing.

Language is a guide to 'social reality'. Though language is not ordinarily thought of as of essential interest to the students of social science, it powerfully conditions all our thinking about social problems and processes. Human beings do not live in the objective world alone, nor alone in the world of social activity as ordinarily understood, but are very much at the mercy of the particular language which has become the medium of expression for their society. It is quite an illusion to imagine that one adjusts to reality essentially without the use of language and that language is merely an incidental means of solving specific problems of communication or reflection. The fact of the matter is that the 'real world' is to a large extent unconsciously built up on the language habits of the group. No two languages are ever sufficiently similar to be considered as representing the same social reality. The worlds in which different societies live are distinct worlds, not merely the same world with different labels attached.

The understanding of a simple poem, for instance, involves not merely an understanding of the single words in their average significance, but 
a full comprehension of the whole life of the community as it is mirrored in the words, or as it is suggested by their overtones. Even comparatively simple acts of perception are very much more at the mercy of the social patterns called words than we might suppose. If one draws some dozen lines, for instance, of different shapes, one perceives them as divisible into such categories as 'straight', 'crooked', 'curved', 'zigzag' because of the classificatory suggestiveness of the linguistic terms themselves. We see and hear and otherwise experience very largely as we do because the language habits of our community predispose certain choices of interpretation.

For the more fundamental problems of the student of human culture, therefore, a knowledge of linguistic mechanisms and historical developments is certain to become more and more important as our analysis of social behavior becomes more refined. From this standpoint we may think of language as the symbolic guide to culture. In another sense too linguistics is of great assistance in the study of cultural phenomena. Many cultural objects and ideas have been diffused in connection with their terminology, so that a study of the distribution of culturally significant terms often throws unexpected light on the history of inventions and ideas. This type of research, already fruitful in European and Asiatic culture history, is destined to be of great assistance in the reconstruction of primitive cultures.

The value's of linguistics for sociology in the narrower sense of the word is just as real as for the anthropological theorist. Sociologists are necessarily interested in the technique of communication between human beings. From this standpoint language facilitation and language barriers are of the utmost importance and must be studied in their interplay with a host of other factors that make for ease or difficulty of transmission of ideas and patterns of behavior. Furthermore, the sociologist is necessarily interested in the symbolic significance, in a social sense, of the linguistic differences which appear in any large community. Correctness of speech or what might be called 'social style' in speech is of far more than aesthetic or grammatical interest. Peculiar modes of pronunciation, characteristic turns of phrase, slangy forms of speech, occupational terminologies of all sorts-these are so many symbols of the manifold ways in which society arranges itself and are of crucial importance for the understanding of the development of individual and social attitudes. Yet it will not be possible for a social student to evaluate such phenomena unless he has very clear notions of the linguistic background against which social symbolisms of a linguistic sort are to be estimated. 
It is very encouraging that the psychologist has been concerning himself more and more with linguistic data. So far it is doubtful if he has been able to contribute very much to the understanding of language behavior beyond what the linguist has himself been able to formulate on the basis of his data. But the feeling is growing rapidly, and justly, that the psychological explanations of the linguists themselves need to be restated in more general terms, so that purely linguistic facts may be seen as specialized forms of symbolic behavior. The psychologists have perhaps too narrowly concerned themselves with the simple psychophysical bases of speech and have not penetrated very deeply into the study of its symbolic nature. This is probably due to the fact that psychologists in general are as yet too little aware of the fundamental importance of symbolism in behavior. It is not unlikely that it is precisely in the field of symbolism that linguistic forms and processes will contribute most to the enrichment of psychology.

All activities may be thought of as either definitely functional in the immediate sense, or as symbolic, or as a blend of the two. Thus, if I shove open a door in order to enter a house, the significance of the act lies precisely in its allowing me to make an easy entry. But if I 'knock at the door', a little reflection shows that the knock in itself does not open the door for me. It serves merely as a sign that somebody is to come to open it for me. To knock on the door is a substitute for the more primitive act of shoving it open of one's own accord. We have here the rudiments of what might be called language. A vast number of acts are language acts in this crude sense. That is, they are not of importance to us because of the work they immediately do, but because they serve as mediating signs of other more important acts. A primitive sign has some objective resemblance to what it takes the place of or points to. Thus, knocking at the door has a definite relation to intended activity upon the door itself. Some signs become abbreviated forms of functional activities which can be used for reference. Thus, shaking one's fist at a person is an abbreviated and relatively harmless way of actually punching him. If such a gesture becomes sufficiently expressive to society to constitute in some sort the equivalent of an abuse or a threat, it may be looked on as a symbol in the proper sense of the word.

Symbols of this sort are primary in that the resemblance of the symbol to what it stands for is still fairly evident. As time goes on, symbols become so completely changed in form as to lose all outward connection with what they stand for. Thus, there is no resemblance between a piece of bunting colored red, white, and blue, and the United 
States of America,-itself a complex and not easily definable notion. The flag may therefore be looked upon as a secondary or referential symbol. The way to understand language psychologically, it seems, is to see it as the most complicated example of such a secondary or referential set of symbols that society has evolved. It may be that originally the primal cries or other types of symbols developed by man had some connection with certain emotions or attitudes or notions. But a connection is no longer directly traceable between words, or combinations of words, and what they refer to.

Linguistics is at once one of the most difficult and one of the most fundamental fields of inquiry. It is probable that a really fruitful integration of linguistic and psychological studies lies still in the future. We may suspect that linguistics is destined to have a very special value for configurative psychology ('Gestalt psychology'), for, of all forms of culture, it seems that language is that one which develops its fundamental patterns with relatively the most complete detachment from other types of cultural patterning. Linguistics may thus hope to become something of a guide to the understanding of the 'psychological geography' of culture in the large. In ordinary life the basic symbolisms of behavior are densely overlaid by cross-functional patterns of a bewildering variety. It is because every isolated act in human behavior is the meeting point of many distinct configurations that it is so difficult for most of us to arrive at the notion of contextual and non-contextual form in behavior. Linguistics would seem to have a very peculiar value for configurative studies because the patterning of language is to a very appreciable extent self-contained and not significantly at the mercy of intercrossing patterns of a non-linguistic type.

It is very notable that philosophy in recent years has concerned itself with problems of language as never before. The time is long past when grammatical forms and processes can be naïvely translated by philosophers into metaphysical entities. The philosopher needs to understand language if only to protect himself against his own language habits, and so it is not surprising that philosophy, in attempting to free logic from the trammels of grammar and to understand knowledge and the meaning of symbolism, is compelled to make a preliminary critique of the linguistic process itself. Linguists should be in an excellent position to assist in the process of making clear to ourselves the implications of our terms and linguistic procedures. Of all students of human behavior, the linguist should by the very nature of his subject matter be the most relativist in feeling, the least taken in by the forms of his own speech. 
A word as to the relation between linguistics and the natural sciences. Students of linguistics have been greatly indebted for their technical equipment to the natural sciences, particularly physics and physiology. Phonetics, a necessary prerequisite for all exact work in linguistics, is impossible without some grounding in acoustics and the physiology of the speech organs. It is particularly those students of language who are more interested in the realistic details of actual speech behavior in the individual than in the socialized patterns of language who must have constant recourse to the natural sciences. But it is far from unlikely that the accumulated experience of linguistic research may provide more than one valuable hint for the setting up of problems of research to acoustics and physiology themselves.

All in all, it is clear that the interest in language has in recent years been transcending the strictly linguistic circles. This is inevitable, for an understanding of language mechanisms is necessary for the study of both historical problems and problems of human behavior. One can only hope that linguists will become increasingly aware of the significance of their subject in the general field of science and will not stand aloof behind a tradition that threatens to become scholastic when not vitalized by interests which lie beyond the formal interest in language itself.

Where, finally, does linguistics stand as a science? Does it belong to the natural sciences, with biology, or to the social sciences? There seem to be two facts which are responsible for the persistent tendency to view linguistic data from a biological point of view. In the first place, there is the obvious fact that the actual technique of language behavior involves very specific adjustments of a physiological sort. In the second place, the regularity and typicality of linguistic processes leads to a quasiromantic feeling of contrast with the apparently free and undetermined behavior of human beings studied from the standpoint of culture. But the regularity of sound change is only superficially analogous to a biological automatism. It is precisely because language is as strictly socialized a type of human behavior as anything else in culture and yet betrays in its outlines and tendencies such regularities as only the natural scientist is in the habit of formulating, that linguistics is of strategic importance for the methodology of social science. Behind the apparent lawlessness of social phenomena there is a regularity of configuration and tendency which is just as real as the regularity of physical processes in a mechanical world, though it is a regularity of infinitely less apparent rigidity and of another mode of apprehension on our 
part. Language is primarily a cultural or social product and must be understood as such. Its regularity and formal development rest on considerations of a biological and psychological nature, to be sure. But this regularity and our underlying unconsciousness of its typical forms do not make of linguistics a mere adjunct to either biology or psychology. Better than any other social science, linguistics shows by its data and methods, necessarily more easily defined than the data and methods of any other type of discipline dealing with socialized behavior, the possibility of a truly scientific study of society which does not ape the methods nor attempt to adopt unrevised the concepts of the natural sciences. It is peculiarly important that linguists, who are often accused, and accused justly, of failure to look beyond the pretty patterns of their subject matter, should become aware of what their science may mean for the interpretation of human conduct in general. Whether they like it or not, they must become increasingly concerned with the many anthropological, sociological, and psychological problems which invade the field of language. 